\title{
Facilitating Problem Solving in a University Undergraduate Physics Classroom: The Case of Students' Self-Efficacy
}

\author{
Paul Nnanyereugo Iwuanyanwu ${ }^{1 *}$ (D)
}

${ }^{1}$ North West University, Potchefstroom, SOUTH AFRICA

*Corresponding Author: paul.Iwuanyanwu@nwu.ac.za

Citation: Iwuanyanwu, P. N. (2022). Facilitating Problem Solving in a University Undergraduate Physics Classroom: The Case of Students' SelfEfficacy. Interdisciplinary Journal of Environmental and Science Education, 18(2), e2270. https://doi.org/10.21601/ijese/11802

\section{ARTICLE INFO}

Received: 2 Jan. 2022

Accepted: 18 Feb. 2022

\begin{abstract}
Real-life and work-related situations of the 21st century present complex problems that require graduates to possess the skills to solve problems in challenging and unfamiliar arenas. Students must therefore have the skills to deal with a wide range of problems. Unfortunately, most students struggle to apply their learning to novel problem-solving situations regardless of their self-efficacy beliefs. It appears particularly significant to investigate this phenomenon in the context of physics education. Using a mixed-methods design within a collaborative learning environment (CLE), this study investigated the factors that influence students' selfefficacy in solving conceptual mathematical problems in physics. The primary data sources were the science problem solving questionnaire (SPSQ), the self-efficacy rating scale (SERS), and two semi-structured interview items. The results of multi-level regression and descriptive data analysis revealed students' self-efficacy in solving conceptual mathematical problems in physics $(\beta=.16, p<.01, S E=.065)$. Among all the self-efficacy variables (e.g., mastery experience, vicarious experience, physical arousal, anxiety, and gender), mastery experiences composed the largest amount of unique variance between male and female students (36\% and $21 \%$ ). The regression coefficient showed a significant difference between male $(\beta=.13, p<.01, S E=.02)$ and female $(\beta=.34$, $p<.01, S E=.07)$. Female students reported slightly higher levels of anxiety $(3 \%)$ than male students (2\%) when completing the SPSQ. In terms of physiological states, females reported $7 \%$ and males $1 \%$. The results also showed a strong positive relationship between the instructional approach and student performance $(r=.86$, $p<.001)$. One major implication of this study is that science educators could include appropriate instruction in delivering content courses to potentially support student teachers at the beginning of their science education studies.
\end{abstract}

Keywords: self-efficacy, collaborative learning, mathematics, problem-solving, physics, students

\section{INTRODUCTION}

Research in problem solving has shown that the degree of self-efficacy that students perceive about their own ability to solve problems can significantly affect how well they perform in problem solving tasks (Geifman \& Raban, 2015; Salaza \& Hayward, 2018). According to Bandura (2015), self-efficacy is concerned more with the ease, fluency, confidence and facility demonstrated by an individual in performing a given task. The literature is replete with evidence that self-efficacy is strongly related to academic achievement across several scientific fields (e.g., Juan et al., 2018; Kriek \& Koontse, 2017; Schwab, 2019). In one sense, a student's belief in his or her ability to act in a way that leads to success has been shown to influence personal performance in many domains (Ahn et al., 2017; Toytok \& Gurel, 2019). Since a student's belief in his or her abilities influences goal selection, persistence in the face of difficulties, and, as a result, task performance (Bandura, 2015), educators' primary responsibility in teaching problem solving skills to students is to increase and sustain students' selfefficacy in their learning (Salazar \& Hayward, 2018). Selfefficacy may also be influenced by variances in students' personalities, such as the quality of effort and willingness (physiological arousal) to continue in the activity (Smith \& Hung, 2016), as well as the type of the instructional style in which students conduct the activity (Zee \& Koomen, 2016). Students that have stronger self-efficacy beliefs frequently set goals for themselves and behave motivationally to accomplish these goals (Pamuk et al., 2017). They also believe in their skills to complete assigned tasks well with little or no assistance from others (Lentfer \& Franks, 2015).

Furthermore, researchers have identified mastery and vicarious experiences, among many others, as possible variables affecting students' self-efficacy beliefs and problemsolving abilities (Geifman \& Raban, 2015; Iwuanyanwu \& Ogunniyi, 2020; Salaza \& Hayward, 2018). In terms of problem solving, students' mastery goals refer to their concentration on 
learning a variety of abilities, developing metacognitive methods, and finding new ways to solve problems (Pamuk et al., 2017). Vicarious learning, or experience, refers to influences arising from seeing others engage in an activity or a defined task in which they participate successfully (Bandura, 2012). This means that a student's belief can be raised from watching his peers succeed through sustained effort that he too can succeed at a given task. In addition to that, if students are self-efficacious, mastery goal oriented, and appreciate the value of the learning tasks (Ahn et al., 2017), they are more likely to persevere in the face of difficulties (Jansen et al., 2014). There is evidence in the literature that all of these students' characteristics are strongly related to their ability to solve science problems successfully (Geifman \& Raban, 2015; Lindstrom \& Franks, 2011; Salaza \& Hayward, 2018). The purpose of this study was to investigate the factors that influence students' self-efficacy in solving conceptual mathematical problems in physics in a collaborative learning environment.

\section{REVIEW OF LITERATURE}

Various studies have shown increasing empirical attention on self-efficacy and its relationship to problem-solving (Avargil, 2019; Pamuk et al., 2017; Zulkarnain et al., 2021). One of the fundamental skills required of university undergraduate physics students is problem solving. The demand for this critical skill is driven by the fact that realworld and work-based situations present complex problems to solve (Iwuanyanwu, 2020). In this vein, research has demonstrated that students' aptitude and sense of selfefficacy in problem solving is dependent on how well they are motivated (Geifman \& Raban, 2015; Kriek \& Koontse, 2017; Salaza \& Hayward, 2018). Another study that supports this result was obtained by Salaza and Hayward (2018) who investigated whether problem-solving and academic selfefficacy served as predictors of undergraduate students' motivation, test performance, and expected grade. Results from the study indicate that problem-solving self-efficacy was a predictor of student motivation and test performance.

Research studies have also taken as their main focus the issue of students' and teachers' self-efficacy in learning engagement (Kuo \& Wieman, 2016), motivation and achievement (Sachitra \& Bandara, 2017), instructional strategies (Shoulders \& Krei, 2015), teaching skills (Walter, 2015), and causal attributions in teacher education programmes (Wang et al., 2015). One explanation for the increased interest in student teacher self-efficacy is a belief that teachers who have high self-efficacy influence students' achievements and are more effective teachers (Pamuk et al., 2017). The opposite is true for teachers with lower self-efficacy levels (Pan, 2014). Some reviews of research on self-efficacy by Sachitra and Bandara (2017), Smith and Hung (2016), and Toytok and Gurel (2019) have suggested new ways of raising students' capabilities in performing given tasks. All acknowledged that instructional approaches that support collaborative learning improved students' learning achievements and awareness of problem-solving. Hwang et al. (2018) agree with the view that collaborative knowledge construction mechanism facilitated in a collaborative learning environment has great potential for helping students effectively learn and organize knowledge as well as fostering their awareness of applying the acquired knowledge to dealing with problems.

Furthermore, some studies have suggested that selfefficacy strongly influence the choices students and teachers make in task engagement (Schwab, 2019), the effort they expend in responding to task and how long they persevere regardless of difficulties they surmount in performing the task (Salazar \& Hayward, 2018). Related literature also suggested that if a student engages in an activity or defined task and performs well, then the student is motivated and is likely to decide to perform such an activity in future (Hwang et al., 2018; Schwab, 2019). If, on the other hand, the student performs poorly at a given task, this may lead to his or her unwillingness to participate in such activity in future (Bandura, 2015). Perhaps what should be added here is that a student's enculturation, upbringing, and internalized values are among the other factors that can influence whether or not he or she will participate in the same activity in the future. In addition to the student-related variables, a student who claims that he or she will perform well in solving conceptual mathematical problems in physics (MIP), for example, may consider the extent to which his mathematical ability has enabled him to perform well in the past and the amount of time required to do so. It is reasonable to expect that when a task has been performed personally and frequently in the past, the individual will rely more heavily on his interpretation of the causes of previous performance levels (Kriek \& Koontse, 2017; Pendergast et al., 2011). Unfortunately, for many students, relying on the causes of previous performance levels in solving conceptual mathematical problems in physics, for example, will not happen automatically and will necessitate appropriate coordination of mathematics concepts and skills.

The coordination of mathematics concepts and skills in solving physics problems can take many different forms, including various types of cognitive tasks, models, creative reasoning, facts of the subject matter, the structure that compartmentalizes these facts, strategies under certain given constraints, attitudinal process, rules and principles that may be required for problem organization and solution. In physics problem solving, coordinating mathematics concepts has a different purpose; rather than expressing abstract relationships, it represents meaning about physical systems (Redish \& Kuo, 2015). It is therefore critical to recognize that the relationships between the interacting variables of MIP frequently present a high level of cognitive load during the problem-solving process. When students begin the process of solving a conceptual MIP problem, they bring all they know about the problem into working memory, including domain knowledge resources, rationalization skills, attitudes, and selfregulation skills required for problem solving success (Iwuanyanwu \& Ogunniyi, 2020). Thus, a broader range of cognitive skills and abilities are required for a student to solve conceptual MIP problems, which some students will already have but others may not. For instance, a student may know that the second kinematic equation that relates position to time $\frac{d s}{d t}=v$ came from the derivative of the first kinematic 
equation which relates velocity to time $\frac{d v}{d t}=a$, and that the logical extension of $\frac{d s}{d t}=a \frac{1}{v}$ would lead to $v d v=a d s$, but fail to see that each side of the former equation is explanatorily linked to the integration $\int_{v_{0}}^{v} v d v=\int_{s_{0}}^{s} a d s$ that yields $\frac{1}{2}\left(v^{2}-\right.$ $\left.v_{0}^{2}\right)=a\left(s-s_{0}\right)$.

Although the literature is rich in studies assessing students' and teachers' self-efficacy beliefs in various fields of learning, more insights are needed in establishing students' self-efficacy determinants in a collaborative learning environment. Students need support as they learn new skills, as well as computational reasons for developing the epistemic metacognitive resources required to solve conceptual MIP problems (Kriek \& Koontse, 2017). Prior research indicates that some instructional approaches that provide opportunities for students to solve problems collaboratively are consistently more successful than others in assisting students in developing a high sense of self-efficacy in problem-solving (Pamuk et al., 2017; Pendergast et al., 2011; Toytok \& Gurel, 2019; Zee \& Koomen, 2016). In this regard, a collaborative learning environment (CLE) is a didactic situation in which individuals (e.g., students) are assigned a task or a problem to solve and they do so by searching for understanding, meaning, or solutions, and the sum of the individual solutions yields a collective solution (Geifman \& Raban, 2015; Iwuanyanwu, 2020). Furthermore, working in small groups has been reported to be beneficial for learning, particularly when the task involves solving science problems in a collaborative learning environment (Belland et al., 2011; Iwuanyanwu \& Ogunniyi, 2020; Jonassen, 2011). This study's didactic design is based on the latter instructional approach. Students worked together to complete individual and small group tasks while developing and maintaining a shared understanding of MIP problem solving.

\section{METHOD}

This study employed a mixed-methods approach within a collaborative learning environment, with data collected via the science problem solving questionnaire (SPSQ), the selfefficacy rating scale (SERS), and two semi-structured interview items, as detailed below.

\section{Participants and Ethics}

The study included 40 first-year science education students from a variety of socioeconomic backgrounds, including those with high, middle, and low incomes and ability levels (aged between 18 and 21 years, 19 females and 21 males). The students enrolled in a four-year science education program aimed at preparing secondary school physical science and mathematics teachers. The majority of students live on campus, with a few others living in urban and suburban areas. The Research Ethics Committees approved the study's research proposal. Following that, permission was obtained from the students, which was granted. There are no conflicts of interest in the study.

\section{Research Tools}

Two sets of instruments, namely, SPSQ and SERS, were developed for measuring factors that influence students' selfefficacy in solving conceptual MIP problems. The SPSQ comprised of 12 conceptual MIP problems. The SERS consisted of a rating table for the SPSQ in which students rate their degree of confidence by recording a number from 0 to 100 . The ratings range from cannot do at all (0-40), moderately can do (50) and highly certain can do (60-100). In designing the instruments, various aspects of self-efficacy constructs were considered and how they affect students learning, for example, social cognitive dimension, including mastery approach, vicarious experience, anxiety and physiological states as well as motivational dimension. To examine the sources of students' self-efficacy, four sub-scales were used: The mastery approach (eight items, e.g., "I got a good grade in physics class last term, and so I will always do well in physics"), vicarious experiences (six items, e.g., "Most of the students I admire are good in physics"), physiological states (six items, e.g., "Conceptual MIP problems make me feel uncomfortable and nervous”), and anxiety (five items, e.g., “I feel I can’t solve conceptual MIP problems, coordinating mathematics concepts and skills in science problem solving is too difficult"). In addition, three more items of motivation constructs were included, for example, "Both my High School teachers and my science lecturers believe I can do well in difficult science tasks." To enrich sources of data, the study extended the instruments (the SPSQ and the SERS) to include two semistructured interview items. The purpose of the interview was to gain additional insight into how the students rated the SERS and their actual performance and to gauge their confidence, ease, and ability.

Furthermore, the instruments were reviewed for face, content, and construct validity by two experts in science and mathematics education. Certain aspects of the instruments were refined in response to the two experts' recommendations and were later sent to the experts for final approval. Each instrument item was rated on a scale of 1 to 5 , with items with scores of 4 or 5 retained and those with less than 3 dropped. Following the construction of the first version of the instruments, a pilot study was conducted among students with characteristics similar to those involved in the actual study. The pilot's preliminary findings prompted the revision of one of the instruments, the SERS. Some ambiguous items on the SERS were rewritten, while others were removed, particularly where the majority of respondents checked the same response point. This is due to the fact that such items make no distinction between students. Items on which the vast majority of students check the maximum efficacy category lack sufficient difficulty, challenge, or impediment to distinguish between levels of efficacy. To reduce such bias, the level of difficulty on SERS during the content validity testing was increased by increasing the level of conceptual MIP problems. Cohen's kappa values, an interrater measure of agreement, were ( $k=.88$ for the SPSQ, $k=.79$ for the SERS). As described below, the instruments were deployed for data collection.

\section{Procedure}

This study lasted 16 weeks. The study (2-hour biweekly physics education periods on Tuesdays and Thursdays) 
included a series of teaching and learning science activities in a collaborative learning environment. The baseline and postintervention data collection took two bi-weekly class periods (4 hours in weeks 1 and 15); the interview took a single class period (1 hour in week 16). The teaching of science concepts using a collaborative learning approach took place between weeks 2 and 14. The interconnectedness of teaching and learning (Jonassen, 2011) and how it serves as an enabling teaching strategy to improve students' self-efficacy in solving conceptual MIP problems are discussed further below.

\section{Collaborative Learning Environment}

Students $(N=40)$ were divided into small groups of five, resulting in eight groups $(\mathrm{A}-\mathrm{H})$. Each student, denoted by the letters S1, S2, and so on, is aware of his or her group member identification. As a result, they completed each assigned task in accordance with the various stages of the collaborative learning approach. According to the CLE protocols, a student must:

a. read each conceptual MIP problems, analyze it (show why components within a task have certain MIP applications),

b. plan and implement a solution pathway/method (show why a certain approach would lead to a solution), and

c. verify (provide reasons why a solution they obtained is reasonable).

In order to complete the task, students must develop justifications for their solutions. In doing so, a transition is initiated by any of the three stages they followed: the junction between stages, the appearance of new information or the opportunity to adopt a new problem-solving strategy, or difficulties indicating that a change in approach is required. Individual students engage in coordinating mathematical concepts and skills in physics prior to beginning the three stages and during the actual problem-solving process, as well as during the transition phase. Following completion of the individual tasks, each group was given the same tasks that required them to collaborate, share individual methods used in problem solving, make claims, argue for the best possible solution, share self-confidence, and reflect on the anxiety/difficulty/enjoyment they had encountered, as well as other traits related to their learning of the tasks. When students reached a possible consensus on each task, they provided the best possible solutions by constructing claims and criteria for justifications of the MIP problem solution pathway. When they became stuck in their work, they were encouraged to explain their ideas and strategies in order to progress. Finally, once they had solved the MIP problems (or had given up), they were asked to explain why certain components of the MIP problems demanded their choice strategies or solution pathways. Following completion of these lessons and activities, data was collected using the same SPSQ and SERS instruments (2 hours in two class periods in week 15). For the interview, a leader was chosen from each of the eight groups $(\mathrm{A}-\mathrm{H})$. In week 16, eight respondents were interviewed for 1 hour, and their responses were analyzed using qualitative descriptions.
Table 1. Descriptive statistics for the students' self-efficacy variables

\begin{tabular}{lcccc}
\hline \multirow{2}{*}{ Variables } & \multicolumn{2}{c}{ Baseline test } & \multicolumn{2}{c}{ Post-test } \\
\cline { 2 - 5 } & $\boldsymbol{M}$ & $\boldsymbol{S D}$ & $\boldsymbol{M}$ & $\boldsymbol{S D}$ \\
\hline Self-efficacy & 3.57 & 2.16 & 5.88 & 1.59 \\
\hline Mastery approach & 3.50 & 2.04 & 5.77 & 1.35 \\
\hline Vicarious experience & 1.67 & 1.31 & 3.48 & 1.17 \\
\hline Physiological arousal & 1.59 & 2.33 & 3.39 & 0.98 \\
\hline Anxiety & 4.6 & 2.67 & 2.58 & 0.86 \\
\hline Note $N=40$
\end{tabular}

Note. $N=40$

\section{Data Analysis}

Each student generated data in the form of written solution transcripts. The written solutions were graded based on a scoring rubric adapted from Iwuanyanwu and Ogunniyi (2020). According to the rubric, a solution received four points if the student correctly coordinated and applied mathematical concepts and skills in solving a given problem and producing a justified solution. If a student successfully coordinated and applied mathematical concepts and skills in solving a given problem and producing a partially justified solution, he or she receives three points. A two-point solution to the problem used either correct MIP application or partial mathematical reasoning. If a student demonstrated an understanding of the use of MIP but failed to apply it satisfactorily, the solution received one point. Finally, if the student demonstrated incorrect understanding of the problem or made no attempt, the solution received 0 points. Furthermore, the students' responses to the SERS were coded using Creswell's (2014) coding schemes. The coding was completed independently by the aforementioned experts who reviewed the instruments. The coding scores were then compared, and the reliabilities measured by Cronbach alphas were satisfactory $\alpha=.81$ for the SPSQ and $\alpha=.73$ for the SERS. For the remaining discrepancies, the two experts discussed until they reached a consensus, and the resulting scores were used in computing descriptive and inferential statistical analysis to identify causal attributions of students' self-efficacy in solving conceptual MIP problems in a collaborative learning environment.

\section{RESULTS}

Multi-level regression and descriptive data analysis were used to analyze data from the SPSQ activities and the SERS. Table 1 shows that the mean scores of students' self-efficacy $\left(M_{S E}=3.57, S D_{S E}=2.16\right)$ and mastery $\left(M_{M a s}=3.5, S D_{M a s}=2.04\right)$ at the baseline test do not differ significantly. Similarly, at the end of the study, their mean scores for the same factors $\left(M_{S E}=5.88, S D_{S E}=1.59 ; M_{M a s}=5.77, S D_{M a s}=1.35\right)$ did not differ significantly. It's possible that students are interested in learning because they want to master the SPSQ and SERS activities. Furthermore, there was little difference between the mean scores of their vicarious experience and physiological arousal at the start of the study and the mean scores of the same variables at the end (see Table 1). Another point of interest in this section is the students' anxiety about MIP problem solving. The mean score for their anxiety to perform and persist in learning activities was higher at the start of the study $\left(M_{A}=4.6, S D_{A}=2.67\right)$ than at the end $\left(M_{A}=2.58, S D_{A}=.86\right)$. 
Table 2. Estimates of multi-level regression analyses of students' self-efficacy variables

\begin{tabular}{lccc}
\hline Variables & $\boldsymbol{\beta}$ & Gender $(\boldsymbol{M} ; \boldsymbol{F}) \boldsymbol{U \%}$ & $\boldsymbol{S E}$ \\
\hline Self-efficacy & $.16^{*}$ & 16 & .065 \\
\hline Mastery experience & $.24^{* *}$ & $28 \cup(36 ; 21)^{1}$ & .13 \\
\hline Vicarious experience & $.17^{* *}$ & $(1 ; 2)$ & .07 \\
\hline Physiological arousal & $-.21^{* *}$ & $(1 ; 7)$ & .014 \\
\hline Anxiety & $.29^{* *}$ & $(2 ; 3)$ & .05 \\
\hline Gender [M; F] & {$[.13 ; .34]^{* *}$} & - & $(.02 ; .07)$ \\
\hline 1 Percentage in parenthesis; ***05;***<.01 & &
\end{tabular}

${ }^{1}$ Percentage in parenthesis; * $p<.05 ; * * *<.01$

Furthermore, the study sought to identify the path coefficients in order to determine the proportion of variation in students' performance that could be attributed to the CLE. The analysis results show that there was a strong positive relationship between the instructional approach and the performance of the students $(r=.86, p<.001)$. Further to that, the root mean square error of approximation was used as an informative estimate of CLE fit, with $p<.05$ indicating good fit and $p<.10$ indicating poor fit.

The regression coefficients ( $\beta$ coefficients) represent the CLE's independent contribution to predicting the dependent variables. Each source of self-efficacy was found to be significantly related to students' ability to coordinate and apply mathematics concepts and skills required to solve conceptual MIP problems. According to the results in Table 2, a significant difference was found for all variables, including students' self-efficacy $(\beta=.16, p<.01, S E=.065)$ male students $(\beta=.13, p<.01, S E=.02)$ and female students $(\beta=.34, p<.01$, $S E=.07)$. Similarly, the mastering approach of male and female students differed significantly on average. These findings were confirmed by structure coefficients and uniqueness indicators, with mastery approach accounting for the largest percentage of unique variance in each case: $28 \%$ for the entire sample $(N=40)$; $36 \%$ of male students have more mastery experience than female students (21\%). Furthermore, female students reported higher levels of conceptual MIP problem-solving anxiety (3\%) than male students (2\%). In terms of physiological states, this was similar (females at $7 \%$ and males at $1 \%$ ). The sorts of causal attributions identified in the CLE context were detailed in the next section to further elucidate these findings.

\section{Students' Responses to Interviews}

Two questions were asked during the interview: (a) How would you compare your SERS confidence ratings to your actual performance on the SPSQ?

A three-item rating scale was employed to answer the first interview question:

1. Overestimation: My actual performance is lower than my rating;

2. Underestimation: My actual performance is greater than my rating; and

3. Moderate: My actual performance and my rating are comparable.

The following are extracts from the students' responses:

S21 (Group A): Overestimation, my actual performance is lower than my rating.
S6 (Group B): Overestimation, my actual performance is lower than my rating.

S29 (Group C): Moderate, my rating and actual performance matched.

S15 (Group D): Underestimation, my actual performance is higher than my rating.

S18 (Group E): Moderate, my rating and actual performance matched.

S10 (Group F): Overestimation, my actual performance is lower than my rating.

S5 (Group G): Overestimation, my actual performance is lower than my rating.

S17 (Group H): Underestimation, my actual performance is higher than my rating.

Given the foregoing, it is of interest to determine which self-efficacy variables correctly predicted the students' ability to solve the SPSQ items in terms of these categorizations: overestimation, underestimation, and moderate. The emphasis is on how the self-efficacy determinant(s) give rise to any of the categorizations. This is further investigated in the following question: (b) Based on the answer you gave to the first question, what do you think accounts for your current level of confidence and comfort solving conceptual MIP problems?

The excerpts below help to demonstrate the relative frequency with which students experience their learning to solve conceptual MIP problems in a CLE setting. The students appeared to be very accomplished in the practice of each stage of CLE; they became aware of how to behave and thrive in this arena. They were aware of the practice's goals, and they shared expectations, allowing them to work collaboratively towards the goals. Here are some excerpts from conversations that illustrate the point.

S21 (Group A): ... please ask me later ... not ready!

S29 (Group C): I was impressed with how well my group worked together. Collaborating with my group members to tackle problems, I have acquired diverse approaches to thinking about and solving conceptual MIP problems. I remembered scoring 50 or higher in my confidence ratings of the SERS items, and given my overall performance in the last quarter, I am more or less confident in my ability ... or confidence. Also, my group members had a similar experience, though there are some differences because we are not all equal in our abilities; some are smarter than others, particularly Jacques (pseudonym), who is very good.

S15 (Group D): I appreciate the new approach; after going through it, I feel confident in using arguments to solve physics problems. When I'm solving conceptual MIP problems, I can now give a good explanation. Yes, problem-solving in mathematics is the same way. Before attempting problems, I now have to do self- 
arguments [sic] in my head. In many ways, it assisted me in gaining a different perspective from my colleagues, such as developing a strategic process, gathering relevant facts first, deciding on which formula to use, and applying rules and principles.

S18 (Group E): It was through this new approach that I gained a better understanding of how to solve physics problems. Before, I would simply look for a formula for the variable in question, and once I had it, I would plug other things into the question to find an answer. But now it's different; I read the problem critically and analyze it with reasons, and I don't rush for a formula until I see that my thoughts are reasonable. Many of us were able to correct our errors thanks to the feedback process. It greatly helped in the reinforcing of our arguments both before and after the group presentation. I can say that the new approach has helped me gain confidence.

Students S29, S18, and S15 appear to have benefited greatly from co-construction of shared knowledge and shared understanding with their peers as the process reviewed their own understanding in light of the collective solution they produced (Geifman \& Raban, 2015; Kriek \& Koontse, 2017). They've also become more cognizant of their own ideas.

S21 (Group A): I knew I had the ability to perform well at first, so I rated myself so highly. When I look at my follow-up performance, I get a headache, and I feel bad for not getting the desired grade. I'm not sure what caused this, but after being exposed to the new approach (CLE), I began to reason differently. I no longer jump to conclusions unless I have compelling reasons to do so. I was supposed to have done better than my final grade. But, as it is, others in my group tried, and not too badly ... as for me, I know I will improve in the next assessment.

Although the use of CLE aims to place students' learning in contexts that align with their motivation to perform well, S21's disappointment was physiological, as she described getting a "headache and feeling bad" for not meeting her expectations. The arousal variable increased the intensity of her disappointment because it depends on how aroused her emotions are in relation to her performance. Case S10 has also been identified as a variable in the disappointment emotions. Although slightly different, it is still the likelihood variable, which reflects his belief that if the family issues that confronted him during the tests had not occurred, he would have performed well.

S10 (Group F): First, I rated my confidence based on how enthusiastic I am about science and the new approach that I believed would help me improve. But as the CLE sessions began, I realized I was falling behind; it's a personal issue ... pause ... I can assure you, sir, that I am confident in my abilities. I am more critical now than ever before, and I can express myself much more effectively without being offensive to those who disagree with me.
S5 (Group G): We tried, and for the most of us, our ratings corresponded to our performance. We are becoming more eager to deal with physics problems critically using arguments, and we are gaining confidence in solving physics and mathematics problems carefully. Everything we've been learning since the beginning of the semester is becoming clearer and easier to understand.

S17 (Group H): The new approach encourages us to support one another in the group. We learn to value each other's contributions and approaches of problem solving as a result of this. Everyone wins in our group because every time we solve problems collectively, we improve in one area of the other individually. As you can see, this was evident in our performances.

S17's response underlined the importance of diversity and social views on collaborative learning. This, among other things, justifies the study's use of CLE to foster a collaborative learning environment that boosts students' self-efficacy in solving conceptual mathematics problems in physics. The summary of findings provides additional insights.

\section{DISCUSSION}

The purpose of this research was to gain insight into students' self-efficacy in solving conceptual mathematical problems in physics through collaborative learning. The findings revealed a link between students' self-efficacy and the didactic instruction in which they demonstrate self-efficacy qualities. There was evidence of heterogeneity in students' self-efficacy and its causal attribution in relation to their achievements at the beginning and end of the study (Table 1). However, for some students, emotional factors such as mastery, physiological arousal, and vicarious learning play a role in their predictive utility, and it is believed that these factors indicate a variance overlap between tests. In line with earlier research (Kim et al., 2016; Kruger \& Dunning, 2009), the current study found that one of the reasons students tend to overestimate their performance capability is due to unique variables associated to the students (e.g., see comments from S21 and S10). Overestimation is defined as rating one's capability on a scale of 60-100 percent of "highly certain can do" and then falling short of the rated scale on actual performance, according to the findings of this study. Underestimation is defined as rating one's capability on a scale of 0-40 of "cannot do at all" and performing above the rated scale on actual performance. At 50 , the capability rate was deemed moderate. Data gathered from activities completed by students revealed that two-thirds found their learning through CLE meaningful, the reminder demonstrated a high level of anxiety, along with emotional reactions or dissatisfaction with the prospect of an unfavorable outcome of their SPSQ performance. This implies that failing to meet their objectives hampered their attitudinal process in the pursuit of the desirability variable. S21, for example, believed that her poor performance was due to her failure to complete the assigned tasks. This belief appears to be a causal attribute of her selfefficacy. 
Over $33 \%$ of the students overestimated their performance, while $54 \%$ underestimated it. The remainder were on a more moderate scale. 22 of 40 students correctly coordinated and applied mathematics concepts and skills required to solve conceptual mathematical problems in physics. Thus, solving conceptual MIP problems in a CLE setting provided students with more motivation to learn and a wider range of skills, including the ability to organize and solve problems than was previously possible. For example, students S29 and S17 from groups $\mathrm{C}$ and $\mathrm{H}$ stated that they struggled at the start of collaborative learning sessions, but that with time and the immediate feedback they received from watching other groups present their work, they began to learn from them. This means that these students' self-efficacy beliefs were formed through the vicarious experience of observing other groups perform tasks. In other words, they used the knowledge they gained through vicarious learning to assess their own chances of success at the same or similar tasks (Pan, 2014). Receiving immediate feedback was found to increase self-efficacy, as evidenced by S18's response (from group E), and thus supported previous findings (Kriek \& Koontse, 2017; Pendergast et al., 2011; Sachitra \& Bandara, 2017; Toytok \& Gurel, 2019). This has also been linked to physiological arousal (anxiety or motivation) to continue participating in an activity (Smith \& Hayward, 2018), which includes personal and environmental factors such as previously held self-beliefs (Smith \& Hung, 2016). The perceived difficulty of the SPSQ, effort expended in tasks by students, and assistance received in task completion are some of the factors highlighted in the existing literature.

Furthermore, the results in Table 2 show that male and female students performed differently. This finding supports the corroborated judgments they made about their ability to solve conceptual MIP problems, and thus reflects their overall sense of self-efficacy. It is possible that the differences were caused by differences in the students' self-efficacy perceptions. Previous research has found that female students (regardless of their own potential) believe science is a subject better suited to their male counterparts (Jansen et al., 2014; Sachitra \& Bandara, 2017). Another possible explanation is that students who admit to having naive beliefs about their ability and lack confidence in their skills are less likely to engage in tasks that require those skills, and they will exert less effort and persistence in the face of difficulty (Bandura, 2015; Pamuk et al., 2017). Based on the results in Table 1 and Table 2 as well as the excerpts from the interview data, it can be stated that students made significant progress under the instructional approach used in the study and that these changes are qualitatively different for skilled and less skilled conceptual MIP problem solvers while a problem is being solved. An important goal appears to be that assessing students' self-efficacy can provide educators with additional insights about their students' subsequent performance; insights that go beyond what can be obtained simply by assessing prior knowledge (Pan, 2014; Schwab, 2019).

\section{CONCLUSIONS}

The findings of this study show that various variables depicted in Table 1 as well as didactic instruction in which students demonstrate these variables collaboratively influence students' self-efficacy and its causal attributes. Given this, collaborative learning appears to play an important role in the design of instructional practice for science students or the goal of science curricula activities for students. As a result, science educators, lecturers, and instructors may scaffold science activities in order to support their students' developing abilities. Most importantly, the learning activities should provide a level of challenge that will facilitate efficacybuilding success while minimizing failures that may undermine students' confidence in their new abilities. Although it cannot be stated that all of the students involved in the study achieved their desirability variable in relation to learning all of the activities presented to them, it can be stated that there was a relationship between their overall activity performance and the intrinsic motivational value they acquired while being exposed to the collaborative learning approach. This was a significant improvement in terms of their performance (Table 1). Overall, students improved their ways of thinking, reasoning, analyzing, and solving conceptual MIP problems, resulting in an increase in problem-solving selfefficacy. Whereas the importance of this study lies in understanding students' self-efficacy in relation to their ability to solve conceptual MIP problems in a collaborative learning environment, future studies can design studies to confirm other causal relationships between science problemsolving self-efficacy and motivational beliefs in science achievements in this learning environment. Finally, since selfefficacy contributes to feelings of self-worth and influences performance, changing inaccurate judgments of students' beliefs about their abilities could benefit them.

Author notes: The author agrees with the results and conclusions.

Funding: No external funding is received for this article.

Ethics approval and consent to participate: Not applicable.

Availability of data and materials: All data generated or analyzed during this study are available for sharing when appropriate request is directed to corresponding author.

\section{REFERENCES}

Ahn, H. S., Bong, M., \& Kim, S.-I. (2017). Social models in the cognitive appraisal of self-efficacy information. Contemporary Educational Psychology, 48, 149-166. https://doi.org/10.1016/j.cedpsych.2016.08.002

Avargil, S. (2019). Learning chemistry: Self-efficacy, chemical understanding, and graphing skills. Journal of Science Education and Technology, 28(4), 285-298. https://doi.org/ 10.1007/s10956-018-9765-X

Bandura, A. (2012). On the functional properties of perceived self-efficacy revisited. Journal of Management, 38(1), 9-44. https://doi.org/10.1177/0149206311410606 
Bandura, A. (2015). On deconstructing commentaries regarding alternative theories of self-regulation. Journal of Management, 41(4), 1025-1044. https://doi.org/10.1177/ 0149206315572826

Belland, B. R., Glazewski, K. D., \& Richardson, J. C. (2011). Problem-based learning and argumentation: Testing a scaffolding framework to support school students' creation of evidence-based arguments. Instructional Science, 39(5), 667-694. https://doi.org/10.1007/s11251-010-9148-z

Bing, T., \& Redish, E. (2009). Analyzing problem solving using math in physics: Epistemological framing via warrants. Physical Review Special Topics in Physics Education Research, 5, 1-15. https://doi.org/10.1103/PhysRevSTPER.5.020108

Creswell, J. W. (2014). Research design: Qualitative, quantitative, and mixed methods approaches. SAGE.

Geifman, D., \& Raban, D. R. (2015). Collective problemsolving: The role of self-efficacy, skill, and prior knowledge. Interdisciplinary Journal of e-Skills and Life Long Learning, 11, 159-178. https://doi.org/10.28945/2319

Hwang, G. J., Lai, C. L., Liang, J. C., Chu, H. C., \& Tsai, C. C. (2018). A long-term experiment to investigate the relationships between high school students' perceptions of mobile learning and peer interaction and higher-order thinking tendencies. Educational Technology Research and Development, 66(1), 75-93. https://doi.org/10.1007/s11423017-9540-3

Iwuanyanwu, P. N. (2020). Nature of problem-solving skills for 21st century STEM learners: What teachers need to know. Journal of STEM Teacher Education, 55(1), 4. https://doi.org/ 10.30707/JSTE55.1/MMDZ8325

Iwuanyanwu, P. N., \& Ogunniyi, M. B. (2020). Effects of dialogical argumentation instructional model on preservice teachers' ability to solve conceptual mathematical problems in physics. African Journal of Research in Mathematics, Science and Technology Education, 24(1), 121141. https://doi.org/10.1080/18117295.2020.1748325

Jansen, M., Schroeders, U., \& Lüdtke, O. (2014). Academic selfconcept in science: Multidimensionality, relations to achievement measures, and gender differences. Learning and Individual Differences, 30, 11-21. https://doi.org/10. 1016/j.lindif.2013.12.003

Jonassen, D. (2011). Supporting problem solving in PBL. Interdisciplinary Journal of Problem-Based Learning, 5(2), 95-119. https://doi.org/10.7771/1541-5015.1256

Juan, A., Hannan, S., \& Namome, C. (2018). I believe I can do science: Self-efficacy and science achievement of grade 9 students in South Africa. South African Journal of Science, 114(7/8), 1-7. https://doi.org/10.17159/sajs.2018/20170269

Kim, Y., Kwon, H., Lee, J., \& Chiu, C. (2016). Why do people overestimate or underestimate their abilities? A crossculturally valid model of cognitive and motivational processes in self-assessment biases. Journal of CrossCultural Psychology, 47(9), 1201-1216. https://doi.org/ 10.1177/0022022116661243

Kriek, J., \& Koontse, R. D. (2017). First year physics students' expectations of the role of mathematics in physics. International Journal of Innovation in Science and Mathematics Education, 25(2), 1-16.
Kruger, J., \& Dunning, D. (2009). Unskilled and unaware of it: How difficulties in recognizing one's own incompetence lead to inflated self-assessments. Journal of Personality and Social Psychology, 77(6), 1121-1134. https://doi.org/ 10.1037//0022-3514.77.6.1121

Lentfer, V. S., \& Franks, B. (2015). The redirect behaviour model and the effects on pre-service teachers' selfefficacy. Journal of Education and Practice, 6(35), 79-87.

Lindstrom, C., \& Sharma, M. D. (2011). Self-efficacy of first year university physics students: Do gender and prior formal instruction in physics matter? International Journal of Innovation in Science and Mathematics Education, 19(2), 1-19.

Pamuk, S., Sungur, S., \& Oztekin, C. (2017). A multilevel analysis of students' science achievements in relation to their self-regulation, epistemological beliefs, learning environment perceptions, and teachers' personal characteristics. International Journal of Science and Mathematics Education, 15(8), 1423-1440. https://doi.org/ 10.1007/s10763-016-9761-7

Pan, Y. H. (2014). Relationships among teachers' self-efficacy and students' motivation, atmosphere, and satisfaction in physical education. Journal of Teaching in Physical Education, 33(1), 68-92. https://doi.org/10.1123/jtpe.20130069

Pendergast, D., Garvis, S., \& Keogh, J. (2011). Pre-service student-teacher self-efficacy beliefs: An insight into the making of teachers. Australian Journal of Teacher Education, 36(12), 46-57. https://doi.org/10.14221/ajte.2011v36n12.6

Redish, E. F., \& Kuo, E. (2015). Language of physics, language of math. Science and Education, 25(5-6), 561-590. https://doi.org/10.1007/s11191-015-9749-7

Sachitra, V., \& Bandara, U. (2017). Measuring the academic self-efficacy of undergraduates: The role of gender and academic year experience. International Scholarly and Scientific Research \& Innovation, 11(11), 2443-2448.

Salaza, L. R., \& Hayward, S. L. (2018). An examination of college students' problem-solving self-efficacy, academic self-efficacy, motivation, test performance, and expected grade in introductory-level economics courses. Decision Sciences Journal of Innovative Education,16(3), 217-240. https://doi.org/10.1111/dsji.12161

Schwab, S. (2019). Teachers' student-specific self-efficacy in relation to teacher and student variables. Educational Psychology, 39 (1), 4-18. https://doi.org/10.1080/01443410. 2018.1516861

Shoulders, T. L., \& Krei, M. S. (2015). Rural high school teachers' self-efficacy in student engagement, instructional strategies, and classroom management. American Secondary Education, 44(1), 50-61.

Smith, C. S., \& Hung, L. C. (2017). Using problem-based learning to increase computer self-efficacy in Taiwanese students. Interactive Learning Environments, 25(3), 329-342. https://doi.org/10.1080/10494820.2015.1127818

Toytok, E. H., \& Gurel, H. (2019). Does project children's university increase academic self-efficacy in 6th graders? A weak experimental design. Sustainability, 11(3), 778. https://doi.org/10.3390/su11030778 
Walter, O. (2015). Self-efficacy as an accurate predictor of teaching skills. Journal of Education Research, 9(3), 309-322.
Zulkarnain, F., Zulnaidi, H., Heleni, S., \& Syafri, M. (2021). Effects of SSCS teaching model on students' mathematical problem-solving ability and self-efficacy. International Journal of Instruction, 14(1), 475-488. https://doi.org/10. 29333/iji.2021.14128a 